\title{
Assess the Clinical Efficacy of Streptokinase in Thrombolysed Patients of Acute ST Segment Elevation Myocardial Infarction
}

\author{
N. Swetha Ramya', J. Bhargava Narendra', Veera Raghavulu B ${ }^{1 *}$, M. Satti Babu' ${ }^{1}$, N. Dharma Teja', K. P. Hema Malini², S.S. Prathap ${ }^{3}$ \\ 'Department of Pharm, D, A. U. College of Pharmaceutical Sciences, Andhra University, Visakhapatnam - 530003, Andhra Pradesh, INDIA. \\ 2Department of Cardiology, Andhra Medical College, King George Hospital, Visakhapatnam- 530003, Andhra Pradesh, INDIA. \\ 3Department of Community Medicine KIMS, Amalapuram, Andhra Pradesh, INDIA.
}

\begin{abstract}
Introduction: Acute myocardial infarction is the most important and feared consequence of coronary artery disease. STEMI is the one of that kind and it occurs by formation of a vulnerable plaque from atherosclerosis and transforms into coronary artery thrombosis in the end. Streptokinase has been used as a thrombolytic agent in patients with acute STEMI. It combines with the circulatory plasminogen to form an activator complex and it converts into plasmin, where, the plasmin breaks the fibrin complex in the blood clot. Streptokinase can be given as 1,500,000U a slow I.V infusion over $30 \mathrm{~min}$. Each STEMI subject is different with the aetiology, pain, ST segment elevation. By considering these factors the clinical efficacy of streptokinase will be evaluated. Materials and Methods: A total number of 75 subjects presenting with acute STEMI to the department of cardiology, King George Hospital, Visakhapatnam, and, those were thrombolysed with streptokinase are included in the study. pain was assessed before and 90 min after administration of streptokinase on numerical pain rating scale from 0-10. ST segment resolution was assessed as percentage reduction in ST segment elevation before administration of streptokinase and the reduction of ST segment elevation 90 min after administration of streptokinase. Student
\end{abstract}

$t$-test and chi-square test were applied to evaluate the results by using software SPSS. Results: A significant resolution in the pain and ST segment elevation were identified by comparing the numerical pain rating scale and ST segment elevation on pre and post streptokinase administration. Conclusion: Streptokinase has been shown to have significant effect on pain resolution and ST segment resolution in subjects with acute ST segment elevation myocardial infarction.

Key words: Acute ST segment elevation myocardial infarction, Clinical efficacy, Pain, Streptokinase, ST segment elevation, Thrombolysed subjects.

Correspondence

Veera Raghavulu B, Department of Pharm, D, A. U. College of Pharmaceutical Sciences, Andhra University, Visakhapatnam - 530003, Andhra Pradesh, INDIA.

Phone: 91-9703286362

Email: raghavab27@gmail.com

DOI: 10.5530/jyp.2018.10.73

\section{INTRODUCTION}

Cardiovascular disease has emerged as the single most important cause of death worldwide over the past decade and its frequency is increasing. Acute coronary syndromes form the most important component of the CVD for the sake of immediate treatment strategies such as reperfusion therapies. ACS has been classified as STEMI and NSTEMI. STEMI occurs when a result in complete occlusion of a major epicardial artery. The most effective treatment for STEMI immediately restoring the patency of the occluded artery either by PCI or fibrinolysis. ${ }^{1}$

Fibrinolysis is an important reperfusion strategy in settings where primary PCI cannot be offered immediately to a patient due to unavailability of a cath lab and trained personal. Fibrinolysis prevents nearly 30 early deaths of 1000 patients when they are treated within $6 \mathrm{~h}$ of symptoms onset. Streptokinase is a non-fibrin selective fibrinolytic that acts as occluding thrombus and lysis to restore the patency of the epicardial artery. The study has been undertaken to assess the clinical efficacy of streptokinase, administered in patients presenting with acute STEMI and window period $\leq 12 \mathrm{~h}$ to the Department of Cardiology, KGH, Visakhapatnam.

\section{MATERIALS AND METHODS}

The present study is a prospective observational study conducted during February 2016-August 2016, in King George Hospital, Visakhapatnam which is a 1400 bedded tertiary care medical college hospital. The department of cardiology in King George Hospital established in 1970 was the study site. It is a 70 bedded department providing state of art, cardiac care to the patients of north coastal Andhra. Institutional Ethics Committee of King George Hospital gave the clearance to carry out the study and the study was executed. The study subjects consisted of the patients who were admitted in the department of cardiology during the period of February 2016 to August 2016. The inclusion criteria and exclusion criteria mentioned in the study protocol was strictly followed. All the patients admitted with acute STEMI and thrombolysed with streptokinase, during the study period who had consented for participation were included. The subjects who were not thrombolysed with streptokinase and those who did not give their consent were not included. The study subjects were interviewed and the details were recorded in the pro forma. Information related to window period, risk factors of CAD (diabetes mellitus, hypertension, smoking, alcohol, Body Mass Index, Family History) was recorded. Height, weight, blood pressure and heart rate of the subjects was recorded. Information related to diet consumption was also captured. Investigation reports of relevant blood parameter RBS was recorded. ECG of all the subjects was taken before the administration of streptokinase and $90 \mathrm{~min}$ after administration of streptokinase. Perception of pain was recorded using Numerical Pain Rating Scale before administration of streptokinase and 90 min after administration of streptokinase. Data from all the pro forma was entered in to a template

This is an open access article distributed under the terms of the Creative Commons Attribution-NonCommercial-ShareAlike 4.0 License, which allows others to remix, tweak, and build upon the work non-commercially, as long as the author is credited and the new creations are licensed under the identical terms. 
created in Microsoft excel 2016 and statistical analysis was done using SPSS version 17 .

\section{RESULTS}

The study group consisted of 75 subjects who included 59 (78.7\%) males and $16(21.3 \%)$ female subjects. The mean age of male subjects was 54 years and the female subjects were 56.625 years. Majority of the study subjects consumed mixed diet $90.67 \%$ and only $9.33 \%$ were vegetarians. Among the study subjects $37.33 \%$ were diabetics, $44 \%$ were hypertensive, $41.33 \%$ were smokers, $36 \%$ were alcoholics and $20 \%$ were overweight and obese subjects. Further $21.33 \%$ of study subjects had a family history of CAD (Figure 1). The association between pain perception before streptokinase administration and $90 \mathrm{~min}$ after streptokinase administration with risk factors (Table. 1). The association between ST segment elevation before streptokinase administration and 90 min after streptokinase administration with risk factors (Table. 2).

\section{DISCUSSION}

The major aim of this study is to find out the clinical efficacy of streptokinase. The study conducted mainly based on changes in ST segment elevation and the numerical pain rating scale, before administration of streptokinase and $90 \mathrm{~min}$ after administration of streptokinase. In the present study, a total of 75 subjects with acute STEMI and those were

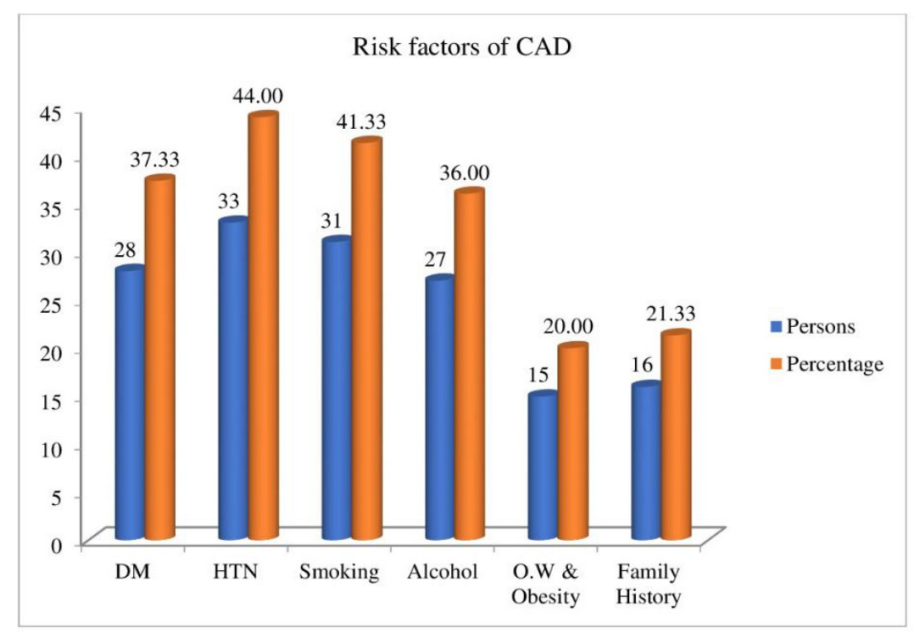

Figure 1: The percentage of risk factors in the study.

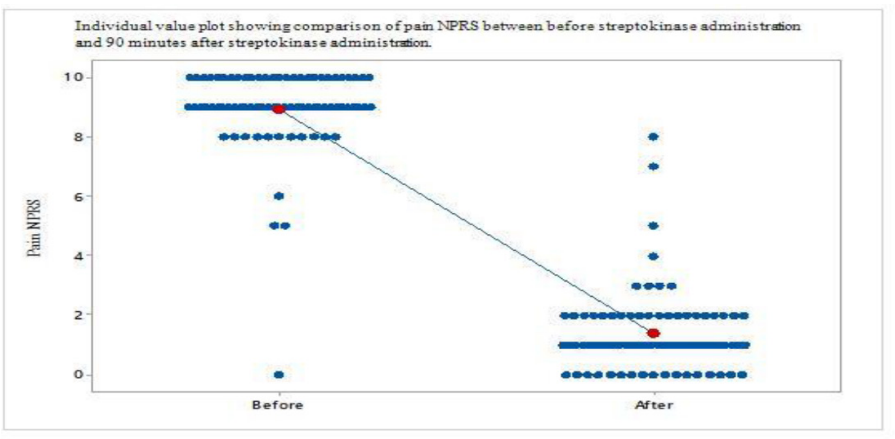

Figure 2: Individual value plot showing comparison of pain NPRS between before streptokinase administration and 90 minutes after streptokinase administration.

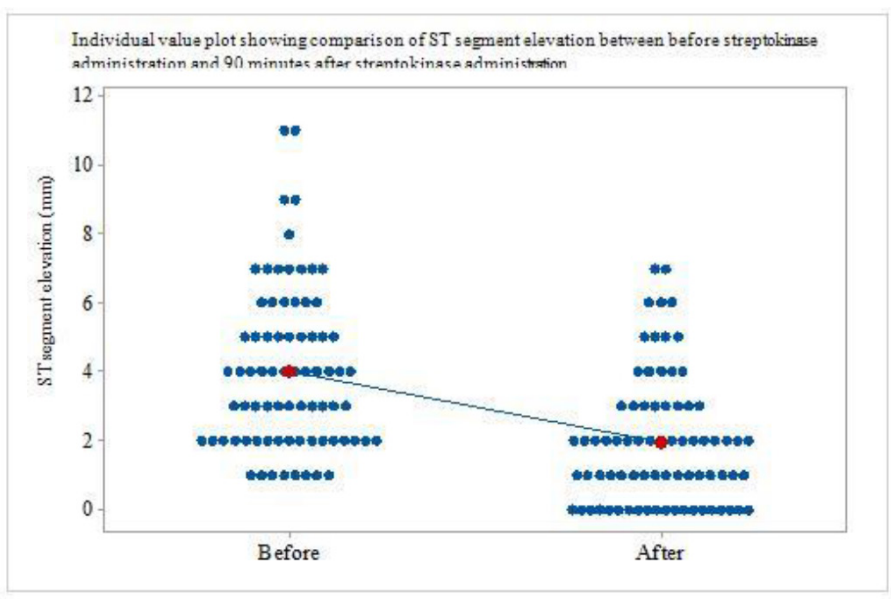

Figure 3: Individual value plot showing comparison of ST segment elevation between before streptokinase administration and 90 minutes after streptokinase administration.

thrombolysed with streptokinase was considered. All risk factors of CAD also included and evaluated.

Streptokinase is the widely used, most feasible and primary treatment option for STEMI in King George Hospital. Likewise, a study by Ruwanthi handava, Arjun Medagama et al., they have also found that, thrombolysis is the primary treatment option for STEMI in Srilanka tertiary care hospital. ${ }^{2}$ Based on global studies, thrombolysis with streptokinase is the common and standalone treatment of reperfusion and it gives less haemorrhagic complication and reduces the risk of stroke as compared with other thrombolytics. ${ }^{3}$ Many other global studies on Streptokinase efficacy also demonstrated conclusively that, streptokinase is the safest, economically feasible, reduces STEMI complications and mortality rate. ${ }^{4-6}$ According to the Brendon J smith comparative study on streptokinase with t-PA, the study concluded that streptokinase can be considered the thrombolytic agent of choice. ${ }^{7}$

In overall study, the window period was reported up to $\leq 12 \mathrm{~h}$, but higher resolution was noted $0-4 \mathrm{~h}$ window period, which is not statistically significant due to less population noted in the period of six months. In a study, conducted by Dr. Girish Ronad and Dr. Rohit present in Gulbarga, India, similar results were obtained. Higher success rate with thrombolysis was seen with window period between $0-4 \mathrm{hrs}$ in the above study. They have found no significant association between frequency of thrombolysis and baseline risk factors. ${ }^{8}$ Although irrespective of the window period, in some subjects the drug streptokinase has shown its efficacy in both pain and ST segment resolution after $4 \mathrm{~h}$ of window period, in accordance with Ulhas Jajoo, Bharathi taskande et al. they have also demonstrated that relief in ongoing coronary pain uniformly distributed irrespective of time lag of streptokinase infusion. ${ }^{9}$

When our study compared the pain NPRS between before administration of streptokinase $( \pm 8.95)$ and $90 \mathrm{~min}$ after administration of streptokinase $( \pm 1.41)$,themeanscoreofpainwasreduced tremendouslyafterthrombolysis and those results are statistically significant $(\mathrm{p}<0.0001)$ (Figure 2$)$. Same as in the comparison of ST segment elevation between before administration of streptokinase $(4.01 \mathrm{~mm})$ and $90 \mathrm{~min}$ after administration of streptokinase $(1.5 \mathrm{~mm})$, the ST segment resolution was seen after thrombolysis and the difference was statistically significant $(p<0.0001)$ (Figure 3$)$. In present study, the overall success rate of thrombolysis $65.84 \%$ is reported. Similarly a study by Anuj R Verma, Swapnil Chillawar, et al. they have also followed the same method to predict the successful clinical outcomes and $60 \%$ of the subjects have with successful clinical reperfusion. ${ }^{10}$ Another study by Rolf Schröder, et.al, they have found that extent of ST segment elevation 
Table 1: The association between pain perception before streptokinase administration and 90 minutes after streptokinase administration with risk factors.

\begin{tabular}{|c|c|c|c|c|c|c|c|c|c|c|}
\hline \multirow[t]{2}{*}{ Contents } & \multicolumn{2}{|c|}{ Diabetes mellitus } & \multicolumn{2}{|c|}{ Hypertension } & \multicolumn{2}{|c|}{ Smoking } & \multicolumn{2}{|c|}{ Alcohol } & \multicolumn{2}{|c|}{ Body Mass Index } \\
\hline & + ve & -ve & +ve & -ve & +ve & -ve & +ve & -ve & $\begin{array}{c}\text { Under Weigh } \\
\text { and Healthy } \\
\text { Weight }\end{array}$ & $\begin{array}{c}\text { Over } \\
\text { Weight } \\
\text { and } \\
\text { Obesity }\end{array}$ \\
\hline No change in pain & 0 & $\begin{array}{c}1 \\
(2.13 \%)\end{array}$ & $\begin{array}{c}1 \\
(2.94 \%)\end{array}$ & 0 & 0 & $\begin{array}{c}1 \\
(2.27 \%)\end{array}$ & 0 & $\begin{array}{c}1 \\
(2.08 \%)\end{array}$ & $\begin{array}{c}1 \\
(1.67 \%)\end{array}$ & 0 \\
\hline Increased pain & 0 & $\begin{array}{c}1 \\
(2.13 \%)\end{array}$ & 0 & $\begin{array}{c}1 \\
(2.43 \%)\end{array}$ & $\begin{array}{c}1 \\
(3.22 \%)\end{array}$ & 0 & 0 & $\begin{array}{c}1 \\
(2.08 \%)\end{array}$ & $\begin{array}{c}1 \\
(1.67 \%)\end{array}$ & 0 \\
\hline$<50 \%$ pain resolution & 0 & $\begin{array}{c}1 \\
(2.13 \%)\end{array}$ & 0 & $\begin{array}{c}1 \\
(2.43 \%)\end{array}$ & $\begin{array}{c}1 \\
(3.22 \%)\end{array}$ & 0 & $\begin{array}{c}1 \\
(3.70 \%)\end{array}$ & 0 & $\begin{array}{c}1 \\
(1.67 \%)\end{array}$ & 0 \\
\hline$\geq 50 \%$ pain resolution & $\begin{array}{c}28 \\
(100 \%)\end{array}$ & $\begin{array}{c}44 \\
(93.6 \%)\end{array}$ & $\begin{array}{c}33 \\
(97.06 \%)\end{array}$ & $\begin{array}{c}39 \\
(95.14 \%)\end{array}$ & $\begin{array}{c}29 \\
(93.56 \%)\end{array}$ & $\begin{array}{c}43 \\
(97.73 \%)\end{array}$ & $\begin{array}{c}26 \\
(96.3 \%)\end{array}$ & $\begin{array}{c}46 \\
(95.84 \%)\end{array}$ & $\begin{array}{c}57 \\
(94.99 \%)\end{array}$ & $\begin{array}{c}15 \\
(100 \%)\end{array}$ \\
\hline
\end{tabular}

Most of the study subjects ( $96 \%$ ) had pain resolution of $\geq 50 \%$ after thrombolysis with streptokinase. However, there is no statistically significant association between pain variation beforestreptokinase administration and 90 minutes after streptokinase administration with each risk factor studied (diabetes mellitus, hypertension, smoking, alcohol and body mass index).

Table 2: The association between ST segment elevation before streptokinase administration and 90 minutes after streptokinase administration with risk factors.

\begin{tabular}{|c|c|c|c|c|c|c|c|c|c|c|}
\hline \multirow[t]{2}{*}{ Contents } & \multicolumn{2}{|c|}{ Diabetes Mellitus } & \multicolumn{2}{|c|}{ Hypertension } & \multicolumn{2}{|c|}{ Smoking } & \multicolumn{2}{|c|}{ Alcohol } & \multicolumn{2}{|c|}{ Body Mass Index } \\
\hline & +ve & -ve & + ve & -ve & + ve & -ve & $+\mathrm{ve}$ & -ve & $\begin{array}{c}\text { Under Weigh and } \\
\text { Healthy Weight }\end{array}$ & $\begin{array}{l}\text { Over Weigh } \\
\text { and Obesity }\end{array}$ \\
\hline $\begin{array}{l}\text { Increased ST } \\
\text { Segment }\end{array}$ & $\begin{array}{c}2 \\
(7.14 \%)\end{array}$ & $\begin{array}{c}4 \\
(14.28 \%)\end{array}$ & $\begin{array}{c}5 \\
(14.70 \%)\end{array}$ & $\begin{array}{c}1 \\
(2.43 \%)\end{array}$ & $\begin{array}{c}3 \\
(9.67 \%)\end{array}$ & $\begin{array}{c}3 \\
(6.81 \%)\end{array}$ & $\begin{array}{c}2 \\
(7.40 \%)\end{array}$ & $\begin{array}{c}4 \\
(8.33 \%)\end{array}$ & $\begin{array}{c}4 \\
(6.66 \%)\end{array}$ & $\begin{array}{c}2 \\
(13.33 \%)\end{array}$ \\
\hline $\begin{array}{c}<50 \% \mathrm{ST} \\
\text { Segment } \\
\text { resolution }\end{array}$ & $\begin{array}{c}4 \\
(14.28 \%)\end{array}$ & $\begin{array}{c}11 \\
(23.4 \%)\end{array}$ & $\begin{array}{c}4 \\
(11.76 \%)\end{array}$ & $\begin{array}{c}11 \\
(26.82 \%)\end{array}$ & $\begin{array}{c}6 \\
(19.35 \%)\end{array}$ & $\begin{array}{c}9 \\
(20.44 \%)\end{array}$ & $\begin{array}{c}7 \\
(25.92 \%)\end{array}$ & $\begin{array}{c}8 \\
(16.66 \%)\end{array}$ & $\begin{array}{c}13 \\
(21.66 \%)\end{array}$ & $\begin{array}{c}2 \\
(13.33 \%)\end{array}$ \\
\hline $\begin{array}{c}\geq 50 \% \mathrm{ST} \\
\text { Segment } \\
\text { resolution }\end{array}$ & $\begin{array}{c}22 \\
(78.58 \%)\end{array}$ & $\begin{array}{c}32 \\
(68.09 \%)\end{array}$ & $\begin{array}{c}25 \\
(73.54 \%)\end{array}$ & $\begin{array}{c}29 \\
(70.77 \%)\end{array}$ & $\begin{array}{c}22 \\
(70.98 \%)\end{array}$ & $\begin{array}{c}32 \\
(72.75 \%)\end{array}$ & $\begin{array}{c}18 \\
(66.68 \%)\end{array}$ & $\begin{array}{c}36 \\
(75.01 \%)\end{array}$ & $\begin{array}{c}43 \\
(71.68 \%)\end{array}$ & $\begin{array}{c}11 \\
(73.34 \%)\end{array}$ \\
\hline
\end{tabular}

Majority of the study subjects (72\%) had ST segment resolution of $\geq 50 \%$ after thrombolysis with streptokinase. It was observed that a higher proportion of diabetics (78.58\%) and hypertensives (73.54\%) had ST segment resolution of $\geq 50 \%$ when compared to non-diabetics and non-hypertensives. There is no statistically significant association observed between ST segment resolution before streptokinase administration and 90 minutes after streptokinase administration with each of this risk factors studied (diabetes mellitus, hypertension, smoking, alcohol and body mass index).

resolution conveys useful early information about the outcome in an individual patient after acute myocardial infarction. ${ }^{11}$ And a similar study by James A de lemos and Eugene Braunwald, assessement of ST segment resolution even earlier than 3-4 h after onset of fibrinolytic therapy, can be used for risk stratification. ${ }^{12}$

The study group consisted of 75 subjects which included 59 (78.7\%) males and $16(21.3 \%)$ female subjects. The mean age of male subjects was 54 years and the female subjects was 56.625 years. Most of the subjects are male (78.7\%) and the mean of age is higher in female which was 56.625 years. similar observation has found by aygul N, Ozdenir K et al. in turkish patients in central Anatolia, in their study, the percentage of female patients increased with increasing age and $80 \%$ of the study subjects are male. ${ }^{13}$ Each risk factor was studied (Diabetes mellitus, hypertension, smoking, alcohol and body mass index). Majority of the study subjects consumed mixed diet $90.67 \%$ and only $9.33 \%$ were vegetarians. Among the study subjects, $44 \%$ were hypertensives, $41.33 \%$ were smokers, $37.33 \%$ were diabetics, $36 \%$ were alcoholics and $20 \%$ were overweight and obese subjects. Further $21.33 \%$ of study subjects had a family history of CAD. Hypertension (44\%) was highly reported among study subject, in associated with another study on hypertension, they have also described that hypertension is highly prevalent in India. ${ }^{14}$ Smoking $(41.33 \%)$ was the second most reported parameter, then diabetics $(37.33 \%)$ and alcoholics are (33\%) respectively. These each risk factor was compared with changes in coronary pain resolution and ST segment resolution. Majority of the study subjects (96\%) had pain resolution of $\geq 50 \%$, after thrombolysis with streptokinase, same as, $72 \%$ of the study subjects had $\geq 50 \%$ ST segment resolution after thrombolysis with streptokinase. Though, Hypertension is reported as a prevalent risk factor, it has shown an paradoxic effect that, hypertensive subjects has shown with higher ST segment resolution than in non-hypertensive subjects, this point is collaborated with the study conducted by Yun Lin, Weiqi Pan et al. in china, they have found the same paradoxic effect with the hypertension. ${ }^{15}$ The same condition is also repeated with diabetes, the diabetic subjects have shown higher ST segment resolution, when compared with nondiabetics, the similar paradoxic effect was also found in the study performed by Krinsley JS and Fischer M. ${ }^{16}$ Another observation that, we have found from the present study that, the number of female subjects $6(37.5 \%)$ and male subjects $21(36 \%)$ with diabetes mellitus are almost equal in percentage, this statement is conjoined with a study on diabetes in STEMI, they have also got the similar results that chances of STEMI 
are almost equal in both male and female. ${ }^{17}$ In present study, smoking is reported as a second major risk factor. The non-smokers have shown a higher pain and ST segment resolution than in smokers, it has been describing that smoking can be the major impact on STEMI, a global study have also described the similar statement that, non-smokers are more beneficial than smokers on thrombolytic therapy. ${ }^{18}$ Likewise, non-alcoholics have shown higher pain and ST segment resolution than alcoholics, consumption of alcohol can affect the thrombolytic therapy.

\section{CONCLUSION}

In conclusion, our study has shown a higher number of males as compared with females, presenting with acute myocardial infarction. Hypertension and smoking form the most common risk factors, seen in $44 \%$ and $41 / \%$ of the patients respectively. Diabetes mellitus was seen in $37 \%$ of the subjects. There is a significant pain resolution $(p<0.0001)$ with streptokinase administration. There is a significant resolution in ST elevation $(p<0.0001)$ following streptokinase administration. Given the high efficacy, wider availability, lower cost and fewer haemorrhagic complications, it can be concluded that streptokinase can be used as a first time thrombolysis in our country. ${ }^{19}$

\section{ACKNOWLEDGEMENT}

We acknowledge all the patients who gave consent for this study.

\section{CONFLICT OF INTEREST}

The authors declare no conflict of interest.

\section{REFERENCES}

1. Eugene Branwald, Douglas P.zipes, Peter libly. Global burden of cardiovascular disease. In: Michael Gaziano. Branwald: Heart disease. A Textbook of Cardiovascular Medicine, $6^{\text {th }}$ edition, 1.

2. Ruwanthi Bandara, Arjuna Medagama, Ruwan Munasinghe, Nandana Dinamithra, Amila Subasinghe, Jayantha Herath, et al. Management and outcomes of acute ST segment-elevation myocardial infarction at a tertiary-care hospital in Sri Lanka: an observational study. BMC Cardiovascular disorders. 2015 January 15: 1.

3. Aldo PM, Maria GF, Eugenio S, HarveyW, Frans WW, GianniT. The Risk of Stroke in Patients with Acute Myocardial Infarction after Thrombolytic and Antithrombotic Treatment. The New England Journal of Medicine. 1992;327(1):1-6.

4. Charles H, Hennekens. Role of Aspirin with Thrombolytic Therapy in Acute Myocardial Infarction. Chest Journal. 1990;97(4):151S-5S.
5. Daniel B. Mark, Mark A. Hlatky, Robert M. Clariff, C. et al. Cost Effectiveness of Thrombolytic Therapy with Tissue Plasminogen Activator as Compared with Streptokinase for Acute Myocardial Infarction. The New England Journal of Medicine. 1995;332:1418-24.

6. Masoud S, Hassan S, Hamid S, Masoud P, Katayoun R. Effect of streptokinase on reflow in rescue percutaneous coronary intervention. Arya Atheroscerosis. 2013;9(1):22-8.

7. Brendon JS. Thrombolysis in acute myocardial infarction: analysis of studies comparing accelerated t-PA and streptokinase. Emergency Medicine Journal. 1999; 16(6):407-11.

8. Dr Girish Ronad, Dr Rohit Dixit. Factors influencing the outcome of thrombolysis in acute myocardial infarction. Indian Journal of Basic and Applied Medical Research. 2015;4(3):545-55.

9. Ulhas J, Bharathi T, Sameeryelwatkar, Rakesh K. Resolution of Coronary Pain and Settelement of elevated ST segment After Streptokinase Thrombolysis in Maiden ST Segment Elevated Myocardial Infarction (STEMI) as a Marker of Prognosis.

10. Anuj RV, Swapnil C, Kamble TK, Sourya A. Clinical Markers of Reperfusion in Patients with Acute Myocardial Infarction and its Prognosis Significance. International Journal of Recent Surgicals and Medical Sciences. 2016;2(2):90-5.

11. Rolf S, Rüdiger D, Thomas B, Karl W, Thomas L, Ulrich $T$, et al. Extent of early ST segment elevation resolution: A simple but strong predictor of outcome in patients with acute myocardial infarction. Journal of the American College of Cardiology. 1994;24(2):384-91.

12. James AL, Eugene B. ST segment resolution as a tool for assessing the efficacy of reperfusion therapy. Journal of the American College of Cardiology 2001;38(5):1283-94.

13. Nazif A, Kurthuluş Ö, Adnan A, Meryem UA, Mehmet AD. Mehmet AV, et al. Prevalence of risk factors of ST segment elevation myocardial infarction in Turkish patients living in Central Anatolia. The Anatolian Journal of Cardiology. 2009;9(1):3-8.

14. Ragupathy A, Nanda KK, Hira P, Hassan K, Oscar H. Franco, Emanuele Di Angelantonio, et al. Hypertension in India: a systematic review and meta-analysis of prevalence, awareness, and control of hypertension. Journal of Hypertension. 2014;32(6):1170-7.

15. Yun L, Weiqi P, Shangqiu N, Xianto S, Zening J, Shuzheng L. Prevalence and management of hypertension in patients with acute coronary syndrome vary with gender: Observations from Chinese registry of acute coronary events (CRACE). Molecular Medicine Reports. 2013;8:173-7.

16. James SK, Molly F. The diabetec paradox: Diabetes is not independently associated with mortality in critically ill patients. Hospital Practice. 2012;40(2):31-5.

17. Javed IM, Azhar M, Tariq JM, Ifaat T. Study on ST Segment Elevation Acute Myocardial Infarction in Diabetic and Non-Diabetic Patients. Pakistan Journal of Medical Sciences. 2008;24(6):786-91.

18. Tomasz R, Zbigniew S, Artur D, Jacek S. Dubiel, Dariusz Dudek. Impact of smoking status on outcome in patients with ST segment elevation myocardial infarction treated with primary percutaneous coronary intervention. Journal of Thrombosis and Thrmbolysis. 2012;34(3):397-403

19. Jamshed D, Prasant KS, Rakesh KS, Anil D, Rajneesh K, Krishna A Mu, et al. Role of thrombolysis in reperfusion therapy for management of AMI: Indian scenario. Indian Heart Journal. 2013;65(5):566-85.

Article History: Submission Date : 18-12-2017; Revised Date : 10-01-2018; Acceptance Date : 07-05-2018.

Cite this article: Ramya NS, Narendra JB, Raghavulu VB, Babu MS, Teja ND, Malini KPH, Prathap SS. Assess the Clinical Efficacy of Streptokinase in Thrombo-

lysed Patients of Acute ST Segment Elevation Myocardial Infarction. J Young Pharm. 2018;10(3):330-3. 